\title{
Tracking Spore-Forming Bacterial Contaminants in Fluid Milk-Processing Systems
}

\author{
J. R. Huck, B. H. Hammond, S. C. Murphy, N. H. Woodcock, and K. J. Boor ${ }^{1}$ \\ Milk Quality Improvement Program, Department of Food Science, Cornell University, Ithaca, NY 14853
}

\begin{abstract}
The presence of psychrotolerant Bacillus species and related spore formers (e.g., Paenibacillus spp.) in milk has emerged as a key biological obstacle in extending the shelf life of high-temperature, short-time pasteurized fluid milk beyond $14 \mathrm{~d}$. A recently developed $r p o B$ DNA sequence-based subtyping method was applied to characterize spoilage bacteria present in raw milk supplies for 2 processing plants, and to assess transmission of these organisms into pasteurized products. Thirty-nine raw milk samples and 11 pasteurized product samples were collected to represent the processing continuum from incoming truck loads of raw milk to packaged products. Milk samples were held at $6^{\circ} \mathrm{C}$ for up to $16 \mathrm{~d}$ and plated for bacterial enumeration at various times throughout storage. Among the 88 bacterial isolates characterized, a total of $31 \mathrm{rpoB}$ allelic types representing Bacillus and Paenibacillus spp. were identified, including 5 allelic types found in both raw milk and finished product samples. The presence of the same bacterial subtypes in raw and commercially pasteurized milk samples suggests that the raw milk supply represents an important source of these spoilage bacteria. Extension of the shelf life of high-temperature, shorttime pasteurized fluid milk products will require elimination of these organisms from milk-processing systems.
\end{abstract}

Key words: milk, Bacillus, Paenibacillus, bacterial subtyping

\section{INTRODUCTION}

The presence of psychrotolerant endospore-forming bacteria (e.g., Bacillus and Paenibacillus spp.) in HTST pasteurized fluid milk has emerged as a key hurdle to extending product shelf life beyond $14 \mathrm{~d}$ (Meer et al., 1991; Fromm and Boor, 2004; Durak et al., 2006; Huck et al., 2007). Because of the ability of endospore-forming

Received March 13, 2007.

Accepted June 13, 2007.

${ }^{1}$ Corresponding author: kjb4@cornell.edu bacteria to survive pasteurization, the presence of these microorganisms in raw milk represents a major potential cause of milk spoilage (Collins, 1981), particularly because these organisms can survive multiple different stresses and, following germination, can grow over broad ranges of $\mathrm{pH}$, temperature, and water activities (van Netten and Kramer, 1992). Raw milk has been recognized as a source of psychrotolerant endosporeforming bacteria contributing to packaged fluid milk product spoilage (Meer et al., 1991). In particular, a study conducted in 2 fluid milk-processing plants in New York State (NYS) showed that these microbial contaminants can be transmitted within a processing plant, from raw milk storage tanks to packaged products (Huck et al., 2007). In addition to introduction of these organisms through the raw milk supply, the presence and persistence of Bacillus and Paenibacillus spp. in the dairy-processing plant environment, which can result in milk contamination from sources within the plant, also can contribute to the presence of these spoilage microorganisms in finished products (te Giffel et al., 1996; Lin et al., 1998). As a consequence, controlling and eliminating these heat-resistant spoilage bacteria is likely to be considerably more challenging than controlling fluid milk spoilage organisms that enter solely through postpasteurization routes.

Bacillus and related genera represent a heterogeneous taxonomic group of gram-positive, rod-shaped, endospore-forming bacteria (Ash et al., 1991) characterized by a wide range of genetic and physiological traits, with variation in cell wall structure, DNA base composition (\% mol G $+\mathrm{C})$ and ability to metabolize carbohydrates (Sneath, 1986; Claus and Fritze, 1989). A number of bacteria initially classified as Bacillus spp. recently have been reclassified into new genera (Pettipher et al., 1997; Eiroa et al., 1999; Guinebretiere et al., 2001; Fromm and Boor, 2004; Huck et al., 2007), including a number that are recognized as contributing to food and beverage spoilage [e.g., Paenibacillus (Ash et al., 1993) and Alicyclobacillus (Wisotzkey et al., 1992)]. Although conventional phenotypic characterization methods (e.g., cellular and spore morphology, gram staining, and biochemical tests) are useful for initial identification 
and characterization of Bacillus and related genera (Logan and Berkeley, 1984), these methods may not provide the sensitive differentiation needed to facilitate tracking of contaminants through processing systems, particularly for the 16S ribosomal RNA (rRNA) group 3 bacilli (i.e., Paenibacillus spp.; Pires and Seldin, 1997; Odumeru et al., 1999; Guinebretiere et al., 2001; Teng et al., 2003; Durak et al., 2006).

Molecular subtyping methods, which allow the differentiation of subtypes within a bacterial species, can provide sensitive tools for tracking contamination sources (Kabuki et al., 2004), including endospore-forming bacteria (Durak et al., 2006; Huck et al., 2007). A variety of molecular subtyping methods [e.g., ribotyping, pulsed-field gel electrophoresis (PFGE), and different PCR-based methods] have been used for subtyping bacterial pathogens and spoilage microorganisms (Wiedmann, 2002). Deoxyribonucleic acid sequencingbased subtyping approaches are emerging as rapid, cost-effective, and reproducible methods (Aires-deSousa et al., 2006). Specifically, a newly developed subtyping method for Bacillus and related genera, which is based on DNA sequencing of the $r p o B$ gene, provides a tool for reproducible and economic subtype characterization that can be used to identify the sources and transmission of these spoilage microorganisms from raw materials to finished products (Durak et al., 2006; Huck et al., 2007).

The objective of this study was to determine whether heat-resistant spoilage bacteria present in pasteurized fluid milk products were also present in individual tank truck loads of raw milk used to manufacture those products. To that end, we used the $r p o B$ sequence-based subtyping method (Durak et al., 2006) to characterize the diversity of psychrotolerant endospore-forming bacteria in raw milk tank truck loads and in pasteurized products from 2 fluid milk plants. In addition, molecular subtyping data for isolates collected in this study were compared with subtyping data from isolates collected in a previous study, which traced psychrotolerant endospore-forming bacteria from commingled raw milk silos to pasteurized packaged products (Huck et al., 2007).

\section{MATERIALS AND METHODS}

\section{Milk Sample Collection}

Raw and pasteurized milk samples were collected at 2 fluid milk-processing plants in NYS (plant C and plant M). In each plant, pasteurized product samples were collected throughout one entire production day in January (plant M) or April (plant C) of 2005; raw milk samples were collected to represent the milk that was used to manufacture the finished product samples tested. At both plants, raw milk samples were collected from the milk storage compartments of incoming tank trucks. Raw milk samples $(\sim 300 \mathrm{~mL})$ were collected by each plant's raw milk receiving personnel from each compartment of each tank truck during $1 \mathrm{~d}$ (site A; Figure 1). At plant $\mathrm{M}$, one sample of raw milk $(\sim 300 \mathrm{~mL})$ was collected by plant personnel from each of 2 commingled raw milk silos by using the silos' sampling ports (site B; Figure 1). Packaged product samples representing pasteurized milk processed from the commingled silos were collected from a selection of fillers and product lines; these included skim milk in both half-gallon paperboard and high-density polyethylene packages, $2 \%$ milk in half-gallon paperboard packages, and homogenized milk in half-gallon paperboard and high-density polyethylene packages (site C; Figure 1). All samples were stored and transported under refrigeration until testing.

\section{Microbiological Testing of Milk Samples}

All raw milk samples were evaluated for standard plate counts (SPC) and psychrotrophic bacterial counts (PBC) according to procedures outlined in the Standard Methods for the Examination of Dairy Products (Frank and Yousef, 2004). After milk aliquots were removed for initial microbiological analyses, the remaining milk samples were thoroughly mixed and $200-\mathrm{mL}$ aliquots were transferred into sterile 250-mL screw-capped Pyrex bottles. Samples taken from tank trucks with multiple compartments were commingled such that each test bottle $(200 \mathrm{~mL})$ represented one tank truck. Raw milk samples were then heat treated at $80^{\circ} \mathrm{C}$ for $12 \mathrm{~min}$ to reduce background flora (i.e., vegetative cells) and cooled immediately on ice. Pasteurized milk samples were mixed and $200 \mathrm{~mL}$ was transferred into sterile 250-mL screw-capped Pyrex bottles. All raw milk samples that had been heat treated and all commercially pasteurized milk samples were stored at $6^{\circ} \mathrm{C}$ and plated over their shelf life. For plant C, all milk samples were evaluated for SPC and PBC at d 1, 7, and 14. For plant $\mathrm{M}$, heat-treated raw milk samples were evaluated for SPC and PBC at d 1, 6, and 14 and pasteurized milk samples were evaluated for SPC and PBC at d 3, 8, and 16. For all samples (heat-treated raw and pasteurized) the initial day of shelf life reflected the day of heat treatment (i.e., laboratory raw milk heat treatment or commercial HTST pasteurization).

\section{Bacterial Isolation}

For each 200-mL milk sample, bacterial colonies present on SPC and PBC plated at d 14 or 16 postprocessing were visually examined, and colonies with distinct morphologies (ranging from 1 to 3 colonies per sample) were 


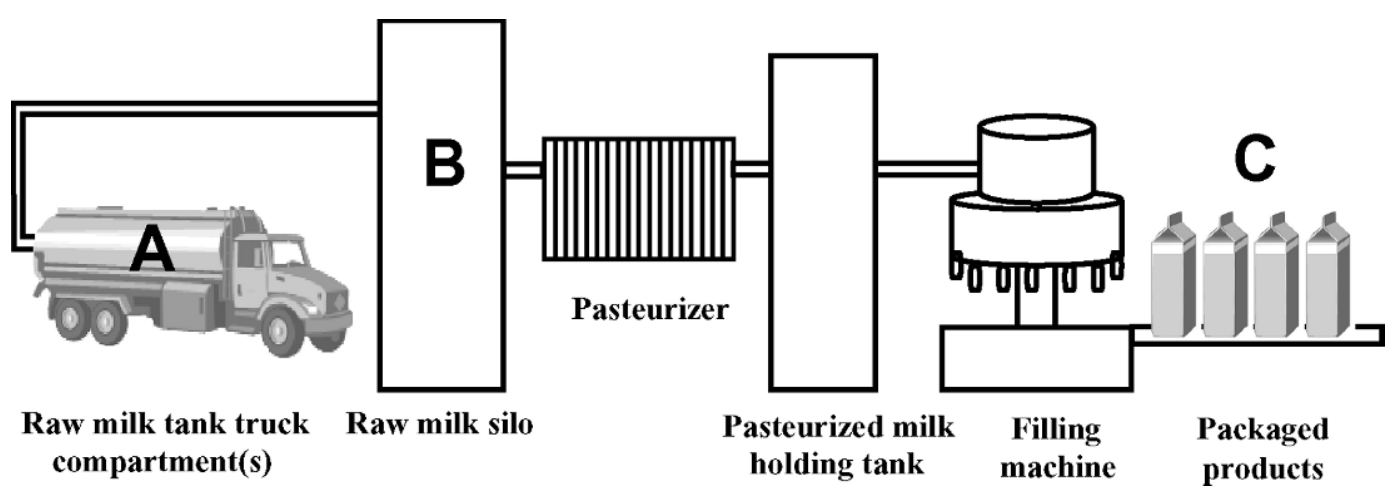

Figure 1. Simplified schematic of fluid milk sample collection points used in this study. Sampling points include (A) raw milk tank truck compartments, (B) raw milk-receiving silos, and (C) packaged products.

selected and streaked for purity on brain heart infusion agar. Purified isolates were characterized for gram reaction by using a 3-step Gram Stain Kit (Becton, Dickinson and Co., Sparks, MD) and subsequently frozen at $-80^{\circ} \mathrm{C}$ in $15 \%$ glycerol.

\section{rpoB Sequencing}

A total of 101 isolates were further characterized by molecular subtyping (39 and 62 isolates from plants C and $\mathrm{M}$, respectively). All isolates from plant $\mathrm{C}$ were obtained from samples plated at d 14. For plant M, isolates from heat-treated raw milk samples were obtained from samples plated for SPC at d 14 postheating, whereas isolates from pasteurized milk samples were obtained from samples plated on d 16 postprocessing.

Subtyping was performed by determining the DNA sequence for a 632-nucleotide (nt) fragment of the rpo $B$ gene, which encodes the beta subunit of RNA polymerase, by using the rpoB PCR primers described by Drancourt et al. (2004) as detailed by Durak et al. (2006). This method was selected because it allows for phylogenetic characterization of isolates in addition to subtype identification, and because it is more economical than most banding pattern-based methods such as ribotyping or PFGE (Kabuki et al., 2004). Briefly, purified DNA for PCR was prepared for each isolate from overnight brain heart infusion cultures by using protocol D of the QIAmp DNA Mini Kit (Qiagen Inc., Valencia, CA). The $r p o B$ PCR products were purified by using the QIAquick PCR Purification Kit (Qiagen Inc.) and quantified by using a NanoDrop ND-1000 spectrophotometer (Nanodrop Technologies, Wilmington, DE). Bidirectional sequencing with PCR primers and Big Dye Terminator chemistry was performed at Cornell University's BioResource Center (Ithaca, NY). Deoxyribonucleic acid sequences were assembled and proofread in SeqMan (Lasergene, DNAstar, Madison, WI) and only high-quality, double-stranded sequence data were used for further analyses. Sequences were aligned in MegAlign (Lasergene, DNAstar) and 632-nt rpoB fragments (corresponding to nt 2,455 to 3,086 of the 3,534-nt rpoB open reading frame of Bacillus cereus ATCC 10987; GenBank AE017194, locus tag BCE_0102) were used for subsequent analyses. The software DnaSP, version 4.0 (Rozas and Rozas, 1999) was used for $r p o B$ allele assignment, and different allelic types (AT) were assigned to gene sequences that differed from each other by one or more nt. Isolates with 2 different AT were considered to represent 2 different molecular subtypes.

\section{Cluster Analyses of гров Sequencing Data}

Identification of related rpoB AT and confirmation of genus and species for the isolates subtyped in this study were accomplished by aligning the $31 \mathrm{rpoB}$ sequences representing the 31 rpo $B$ AT identified in this study along with $r p o B$ sequences representing the 102 rpo $B$ AT previously characterized by Durak et al. (2006) and Huck et al. (2007) (GenBank Accession Numbers EF156897 to EF156925 and EF156999 to EF15702). A phylogenetic tree was constructed by using the neighbor-joining method with 2,000 bootstrap replicates; Streptococcus pyogenes (NC_004070) was used as an outgroup. Phylogenetic analysis was performed by using PAUP, version 4.0 beta 10 (Sinauer Associates, Inc., Sutherland, MA). The 102 previously identified $r p o B$ AT used to construct phylogenetic trees in this study had previously been used to assign isolates to genus (Bacillus and Paenibacillus) and species, where possible, by using both rpoB and $16 \mathrm{~S}$ rDNA sequence data (Huck et al., 2007). The resulting phylogenetic trees support the genus and species identification of the isolates characterized here. 


\section{$16 S$ rDNA Sequencing}

Although the majority of isolates collected in the current study could be characterized to genus and species through phylogenetic analyses with previous rpoB sequence data (Durak et al., 2006; Huck et al., 2007) as described above, 16S rDNA sequencing was used to confirm the genus and species identification of $r p o B$ AT that had not been identified in any of our previous studies. Specifically, one isolate representing each newly identified Bacillus or Paenibacillus spp. rpoB AT was characterized by sequencing the $3^{\prime}$ end of the $16 \mathrm{~S}$ rDNA. In addition, isolates for which the $r p o B$ primers (i.e., those described by Drancourt et al., 2004) did not successfully amplify the targeted $r p o B$ fragments were similarly classified to genus or species with $16 \mathrm{~S}$ rDNA sequencing. The 16S rDNA PCR was performed with primers PEU7 (Rothman et al., 2002) and DG74 (Griesen et al., 1994) as previously described (Fromm and Boor, 2004; Durak et al., 2006). Subsequent DNA sequencing of PCR products was performed with primers PEU7 and P3SH (Ralyea et al., 1998). Purification of genomic DNA, PCR product purification, quantification, sequencing, and sequence assembly were performed as described above for $r p o B$ sequencing. To account for the presence of multiple copies of rRNA operons with different sequences in a given isolate (Klappenbach et al., 2001), 16S rDNA sequences were assembled by using nt ambiguity codes as described by the Nomenclature Committee of the International Union of Biochemistry and Molecular Biology. Final partial 3' 16S rDNA sequences were used for similarity searches against the National Center for Biotechnology Information nt sequence database with the Blast Local Alignment Search Tool (BLAST; McGinnis and Madden, 2004). Genus or species assignments, or both, for specific 16S rDNA sequences were based on the top matches returned by the BLAST search.

\section{Data Curation}

Isolate characteristics and sequence data, along with relevant isolation and sample information, can be accessed through the Pathogen Tracker database at www.pathogentracker.net (Fugett, 2006). GenBank accession numbers for 16S rDNA and $r p o B$ sequences of isolates representing each rpoB AT identified in this study are listed in Table 1.

\section{Statistical Analysis}

Bacterial enumeration data were analyzed by the GLM method in SAS (version 9.1.3, SAS Institute Inc., Cary, NC). For all analyses, log-transformed bacterial count data were used. Analysis of variance was used to test for the effect of plant on raw milk SPC.

\section{RESULTS}

\section{Microbiological Analysis of Raw Milk Quality}

Total bacterial counts for raw milk (with no heat treatment) collected from tank truck compartment samples, as determined by SPC, were significantly different $(P<0.005$; ANOVA) between plant $\mathrm{C}$ (ranging from 3.18 to $6.23 \log \mathrm{cfu} / \mathrm{mL} ; 4.69$ average $\log \mathrm{cfu} / \mathrm{mL}$ ) and plant $\mathrm{M}$ (ranging from 3.43 to $4.93 \log \mathrm{cfu} / \mathrm{mL} ; 4.03$ average $\log \mathrm{cfu} / \mathrm{mL}$ ). Plant $\mathrm{C}$ raw milk $\mathrm{PBC}$ ranged from 3.18 to $6.23 \log \mathrm{cfu} / \mathrm{mL}$ among tank truck compartments (average $\mathrm{PBC}=4.69 \log \mathrm{cfu} / \mathrm{mL}$ ). Raw milk PBC were not performed for milk samples at plant $M$.

\section{Microbiological Analysis of Heat-Treated Raw and Commercially Pasteurized Milk Samples}

Total bacterial counts, as measured by SPC and PBC, of heat-treated raw and commercially pasteurized milk samples that had been stored at $6^{\circ} \mathrm{C}$ were plotted to assess bacterial numbers over time in samples from plants $\mathrm{C}$ and $\mathrm{M}$ (Figures 2 and 3). Within each plant, patterns of bacterial counts, as measured by SPC and PBC, were similar for heat-treated raw milk samples and commercially pasteurized milk samples, confirming previous observations (Huck et al., 2007) that the $80^{\circ} \mathrm{C}$ heat treatment used to treat all raw milk samples prior to refrigerated storage at $6^{\circ} \mathrm{C}$ leaves a residual bacterial population in the raw milk with growth characteristics similar to those in commercially pasteurized milk. Further, because the laboratory-heated milk was filled aseptically into sterile bottles, the fact that bacterial growth patterns in the paired commercial and laboratory-heated samples were essentially identical also suggests that minimal additional post-HTST pasteurization contamination with organisms that are able to grow at $6^{\circ} \mathrm{C}$ occurred in the commercially processed milk products.

Standard plate counts for heat-treated samples of raw milk collected from tank trucks were not significantly different $(P>0.05$; ANOVA) between plants (Figure 2). For plant C, SPC for these heat-treated raw milk samples increased from 2.48 average $\log \mathrm{cfu} / \mathrm{mL}$ on d 1 (1.60 to $3.04 \log \mathrm{cfu} / \mathrm{mL}$; range among 8 samples) to 4.46 average log cfu/mL on d 14 (2.77 to 6.20 log cfu/ $\mathrm{mL} ; 8$ samples). For heat-treated raw milk samples from trucks at plant M, SPC increased from 2.35 average $\log \mathrm{cfu} / \mathrm{mL}$ on d 1 (1.60 to $3.04 \log \mathrm{cfu} / \mathrm{mL} ; 13 \mathrm{sam}-$ ples) to 5.17 average $\log \mathrm{cfu} / \mathrm{mL}$ on $\mathrm{d} 14$ (3.43 to 6.51 $\log \mathrm{cfu} / \mathrm{mL} ; 13$ samples). Standard plate counts for heattreated samples of raw milk collected from 2 silos at 
Table 1. 16S rDNA-based species ID, rpoB allelic type, cluster assignment, and GenBank accession numbers for isolates subtyped in this study

\begin{tabular}{|c|c|c|c|c|}
\hline $\begin{array}{l}\text { 16S rDNA-based species ID } \\
\text { (no. of isolates) }\end{array}$ & $\begin{array}{l}\text { rpoB } \\
\text { allelic } \\
\text { type }^{1}\end{array}$ & $\begin{array}{l}\text { Assigned } \\
\text { cluster }^{2}\end{array}$ & $\begin{array}{c}\text { GenBank } \\
\text { accession } \\
\text { number } \\
\text { for } r p o B \\
\text { sequence }\end{array}$ & $\begin{array}{l}\text { GenBank } \\
\text { accession } \\
\text { number for } \\
\text { 16S rDNA } \\
\text { sequence }\end{array}$ \\
\hline \multicolumn{5}{|l|}{ Paenibacillus spp. } \\
\hline Paenibacillus spp. (10) & 2 & XXII & EF156898 & EF156869 \\
\hline Paenibacillus spp. (3) & 7 & XXII & EF156903 & EF156874 \\
\hline Paenibacillus spp. (1) & 13 & XXII & EF156909 & EF156880 \\
\hline Paenibacillus spp. (21) & 15 & XXII & EF156911 & EF156882 \\
\hline Paenibacillus spp. (2) & 19 & XXII & EF156915 & EF156886 \\
\hline Paenibacillus spp. (4) & 21 & XXII & EF156917 & EF156888 \\
\hline Paenibacillus spp. (8) & 27 & XXII & EF156923 & EF156894 \\
\hline Paenibacillus spp. (6) & 32 & XXII & EF157000 & EF156969 \\
\hline Paenibacillus spp. (2) & 33 & XXII & EF157001 & EF156953 \\
\hline Paenibacillus spp. (3) & 35 & XXII & EF157002 & EF156984 \\
\hline Paenibacillus spp. (1) & 36 & XXII & EF157003 & EF156988 \\
\hline Paenibacillus spp. (1) & 38 & XXII & EF157004 & EF156979 \\
\hline Paenibacillus spp. (1) & 40 & XXII & EF157006 & EF156978 \\
\hline Paenibacillus spp. (4) & $46^{1}$ & XXII & EF203115 & EF203104 \\
\hline Paenibacillus spp. (1) & 50 & XXII & EF157009 & EF156998 \\
\hline Paenibacillus spp. (1) & 30 & XXI & EF156999 & EF156934 \\
\hline Paenibacillus spp. (1) & 39 & XX & EF157005 & EF156962 \\
\hline Paenibacillus spp. (1) & $44^{1}$ & $\mathrm{XX}$ & EF203113 & EF203102 \\
\hline Paenibacillus spp. (1) & $45^{1}$ & $\mathrm{XX}$ & EF203114 & EF203103 \\
\hline Paenibacillus spp. (2) & $51^{1}$ & $\mathrm{XX}$ & EF203118 & EF203107 \\
\hline Paenibacillus spp. (1) & $52^{1}$ & $\mathrm{XX}$ & EF203119 & EF203108 \\
\hline P. borealis $(2)$ & 41 & XVIII & EF157007 & EF156950 \\
\hline P. borealis (2) & $42^{1}$ & XVIII & EF203112 & EF203101 \\
\hline P. amylolyticus (2) & 23 & XVI & EF156919 & EF156889 \\
\hline P. amylolyticus (1) & 48 & XVI & EF157008 & EF156967 \\
\hline P. amylolyticus (1) & $49^{1}$ & XVI & EF203117 & EF203106 \\
\hline \multicolumn{5}{|l|}{ Bacillus spp. } \\
\hline B. pumilus (1) & $47^{1}$ & XI & EF203116 & EF203105 \\
\hline B. weihenstephanensis (1) & 3 & IX & EF156899 & EF156870 \\
\hline Bacillus spp. (1) & $34^{1}$ & VI & EF203110 & EF203099 \\
\hline B. licheniformis (1) & 1 & II & EF156897 & EF156868 \\
\hline B. licheniformis (1) & $31^{1}$ & II & EF203109 & EF203098 \\
\hline
\end{tabular}

plant M (representing commingled milk from all incoming tank truck loads of raw milk tested), increased from 2.49 average $\log \mathrm{cfu} / \mathrm{mL}$ on $\mathrm{d} 1(2.34$ and $2.64 \mathrm{cfu} / \mathrm{mL}$ for samples 1 and 2) to 5.72 average $\log \mathrm{cfu} / \mathrm{mL}$ on $\mathrm{d}$ 14 (5.58 and $5.85 \mathrm{cfu} / \mathrm{mL}$ for samples 1 and 2).

Psychrotrophic bacterial counts measured over the shelf life of the heat-treated samples of raw milk collected from tank trucks differed significantly $(P<0.05$; ANOVA) between plants (Figure 3). For plant C, PBC for the raw milk samples that had been heat treated and then held at $6^{\circ} \mathrm{C}$ increased from 1.23 average log $\mathrm{cfu} / \mathrm{mL}$ on $\mathrm{d} 1(<1.00$ to $1.60 \log \mathrm{cfu} / \mathrm{mL} ; 8$ samples $)$ to 4.20 average $\log \mathrm{cfu} / \mathrm{mL}$ on d 14 (2.51 to $5.89 \log \mathrm{cfu} /$ $\mathrm{mL} ; 8$ samples; Figure 3). For plant M, PBC for these heat-treated raw milk samples increased from $<1.00$ $\log \mathrm{cfu} / \mathrm{mL}$ on $\mathrm{d} 1$ for all 13 samples to 5.76 average log $\mathrm{cfu} / \mathrm{mL}$ on d 14 (3.96 to $6.73 \mathrm{log} \mathrm{cfu} / \mathrm{mL} ; 13$ samples). Psychrotrophic bacterial counts for heat-treated sam- ples of raw milk collected from 2 silos sampled at plant $\mathrm{M}$ increased from $<1.00 \mathrm{log} \mathrm{cfu} / \mathrm{mL}$ on d 1 (2 samples) to 6.51 average log cfu/mL on d 14 (6.43 and $6.58 \mathrm{log}$ cfu/mL for samples 1 and 2).

Standard plate counts for milk from packaged finished products at plant $\mathrm{C}$ increased from 2.17 average $\log \mathrm{cfu} / \mathrm{mL}$ on d 1 (2.08 to $2.30 \log \mathrm{cfu} / \mathrm{mL} ; 5$ samples) to 4.60 average $\log \mathrm{cfu} / \mathrm{mL}$ on d 14 (3.43 to $5.82 \mathrm{log} \mathrm{cfu} /$ $\mathrm{mL} ; 5$ samples). Standard plate counts for milk from packaged finished products at plant $\mathrm{M}$ increased from 2.72 average $\log \mathrm{cfu} / \mathrm{mL}$ on d 3 (2.54 to $2.89 \log \mathrm{cfu} / \mathrm{mL}$; 6 samples) to 5.90 average $\log \mathrm{cfu} / \mathrm{mL}$ on $\mathrm{d} 16$ (4.79 to $6.68 \log \mathrm{cfu} / \mathrm{mL}$; 6 samples; Figure 2).

Psychrotrophic bacterial counts for milk from packaged finished products at plant $\mathrm{C}$ increased from 1.45 average $\log \mathrm{cfu} / \mathrm{mL}$ on d 1 (1.00 to $2.18 \log \mathrm{cfu} / \mathrm{mL} ; 5$ samples) to 4.64 average log cfu/mL on $\mathrm{d} 14$ (3.40 to $6.78 \log \mathrm{cfu} / \mathrm{mL} ; 5$ samples). Psychrotrophic bacterial 


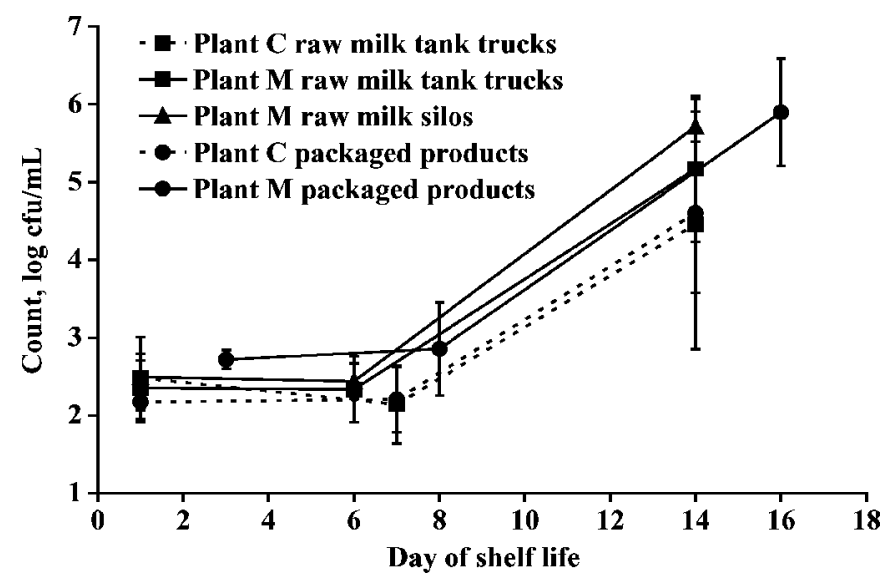

Figure 2. Standard plate counts (SPC) for heat-treated raw milk and pasteurized packaged product samples at plants $\mathrm{C}$ and $\mathrm{M}$. Raw milk samples were collected and heat treated at $80^{\circ} \mathrm{C}$ for $12 \mathrm{~min}$; both heat-treated raw milk and HTST-processed samples were held at $6^{\circ} \mathrm{C}$ and plated over their shelf life. Data points represent average sample SPC from 8 incoming raw milk tank truck loads at plant C, 13 incoming raw milk tank truck loads at plant M, 2 raw milkreceiving silos at plant $M, 5$ packaged product samples at plant $C$, and 6 packaged product samples at plant M. Bars indicate mean \pm $1 \mathrm{SD}$ at each point.

counts for milk from packaged finished products at plant $\mathrm{M}$ increased from $<1.00 \mathrm{log} \mathrm{cfu} / \mathrm{mL}$ on d 3 for all 6 samples to 6.42 average $\log \mathrm{cfu} / \mathrm{mL}$ on $\mathrm{d} 16$ (5.68 to $6.78 \mathrm{log} \mathrm{cfu} / \mathrm{mL} ; 6$ samples; Figure 3).

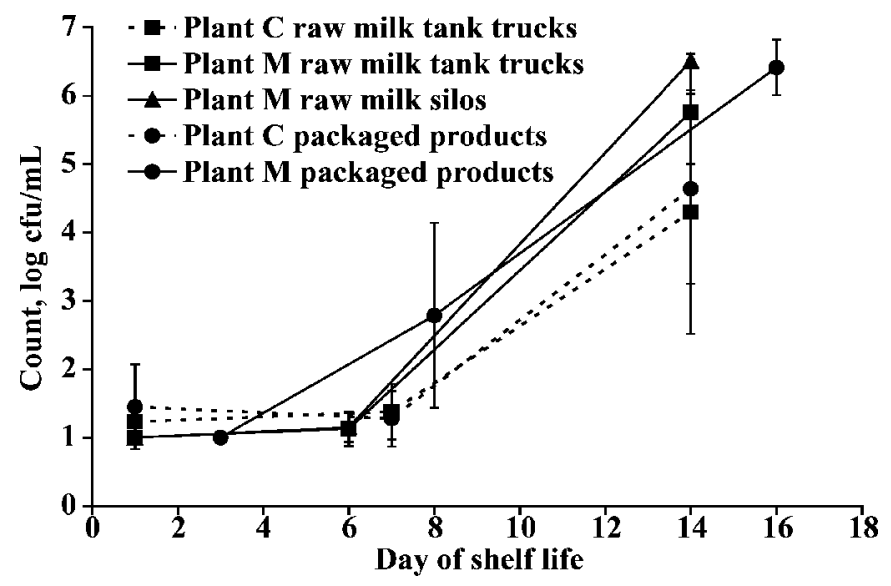

Figure 3. Psychrotrophic bacterial counts obtained for heattreated raw milk and pasteurized packaged product samples at plants $\mathrm{C}$ and M. Raw milk samples were collected and heat treated at $80^{\circ} \mathrm{C}$ for $12 \mathrm{~min}$; both heat-treated raw milk and HTST-processed samples were held at $6^{\circ} \mathrm{C}$ and plated over their shelf life. Data points represent average sample standard plate counts from 8 incoming raw milk tank truck loads at plant C, 13 incoming raw milk tank truck loads at plant M, 2 raw milk-receiving silos at plant M, 5 packaged product samples at plant $\mathrm{C}$, and 6 packaged product samples at plant M. Bars indicate mean $\pm 1 \mathrm{SD}$ at each point.

\section{rpoB Sequencing}

A total of 101 isolates were selected from d 14 and 16 SPC plates for $r p o B$ sequence subtyping (representing 39 and 62 isolates from plants $\mathrm{C}$ and $\mathrm{M}$, respectively). Among these 101 isolates, 88 yielded $r p o B$ products that could be successfully sequenced. For 3 isolates, sufficient growth could not be obtained from cultures that had been frozen; therefore, subtyping was not performed. The remaining 10 isolates, for which the $r p o B$ primers (i.e., those described by Drancourt et al., 2004) did not successfully amplify the targeted $r p o B$ fragments, were subsequently characterized by sequencing the $3^{\prime}$ end of the $16 \mathrm{~S}$ rRNA gene.

Overall, 31 rpoB AT (i.e., subtypes based on different $r p o B$ sequences) were differentiated among the 88 isolates (32 and 56 isolates from plants $\mathrm{C}$ and $\mathrm{M}$, respectively). Eight AT were isolated from both plants, whereas 10 and 14 AT were isolated either at plant $\mathrm{C}$ or at plant $\mathrm{M}$, respectively. A total of $17 \mathrm{rpoB} \mathrm{AT}$ represented only a single isolate, including 7 from plant $\mathrm{C}$ and 10 from plant M. Ten rpoB AT (representing $29.5 \%$ of all isolates subtyped) represented $\geq 2$ and $\leq 5$ isolates. Four rpoB AT (AT 2, 15, 27, and 32) represented more than 5 isolates; these 4 AT represented $51.1 \%$ of all isolates identified.

\section{Cluster Analysis of rpoB Allelic Types}

The $r p o B$ sequences were used in phylogenetic analyses to identify groups of related subtypes (i.e., clusters) and to confirm genus and species identification of isolates. Specifically, $31 \mathrm{rpoB}$ sequences, representing the 31 rpoB AT identified in this study, were aligned with $r p o B$ sequences for the 102 rpoB AT previously characterized by our group (Durak et al., 2006; Huck et al., 2007); this alignment of 133 sequences was then used to construct a phylogenetic tree (Figure 4). All rpoB AT identified in this study grouped into 2 distinct and wellsupported clusters representing the genera Bacillus and Paenibacillus, consistent with our previous findings (Huck et al., 2007). Ten of the rpoB AT identified among the 88 isolates characterized here had not been identified in our previous studies (Durak et al., 2006; Huck et al., 2007). These 10 AT were classified as Bacillus (3 AT) and Paenibacillus spp. (7 AT) AT; all of these 10 "new" rроB AT grouped closely with Bacillus and Paenibacillus spp. clusters previously identified by Huck et al. (2007; Table 1) and could thus be assigned to genus, species, and phylogenetic cluster.

\section{S rDNA Sequencing}

The 16S rDNA sequencing was performed on 20 isolates to provide or confirm taxonomic identification. Ten 


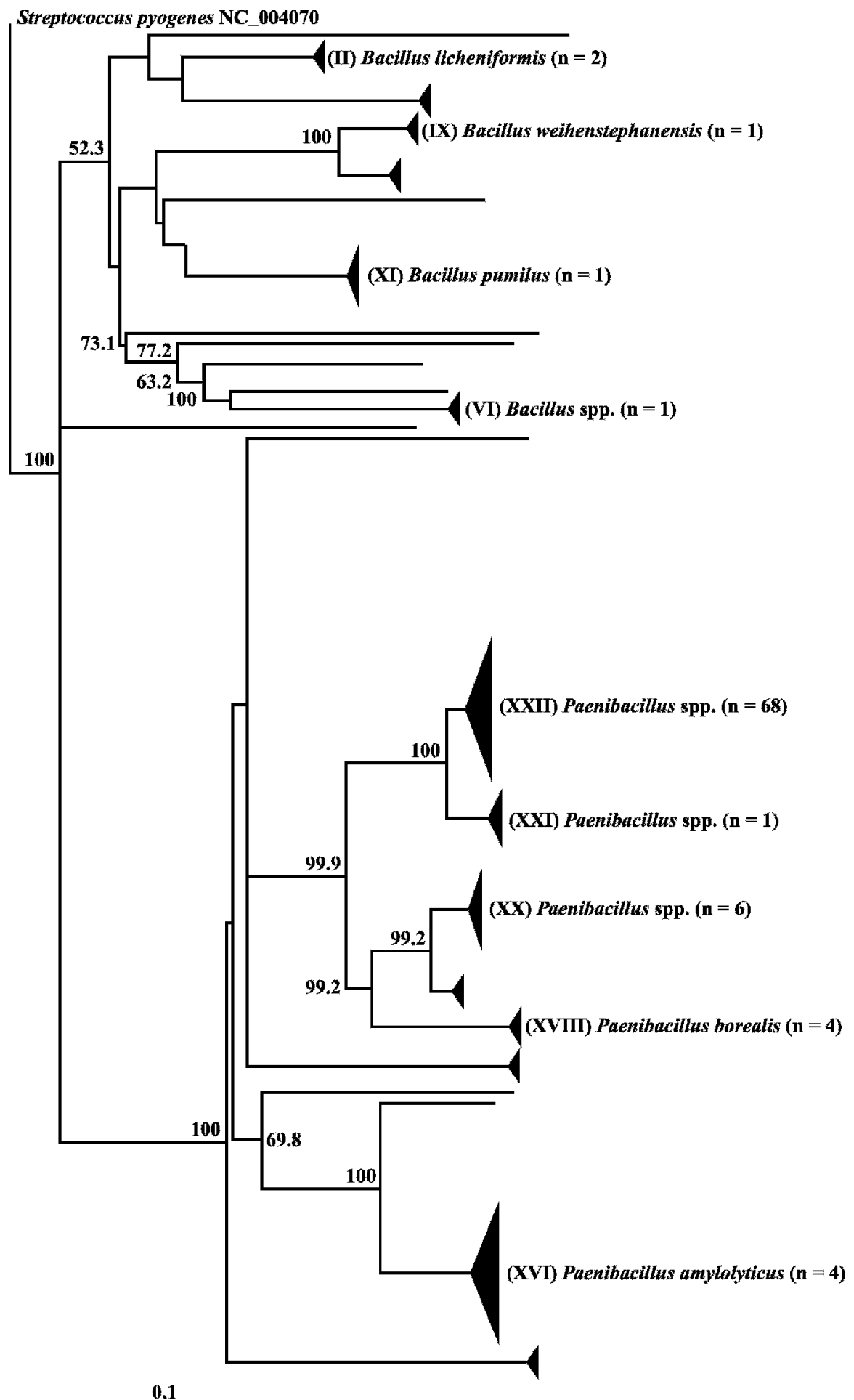

Figure 4. Simplified phylogenetic tree of $r p o B$ sequences representing 114 rpo $B$ allelic types. The tree was constructed by using the neighbor-joining method and 632-nucleotide $r p o B$ fragments; in addition to the 32 rpo $B$ allelic types found here, rpoB allelic types reported by Durak et al. (2006) and Huck et al. (2007) were included in this tree. The rpoB sequence for Streptococcus pyogenes (Gene Bank Accession No. NC_004070) was used as an outgroup. A total of 2,000 bootstrap replicates were performed; only bootstrap values greater than 50 and supporting major branches are shown. Triangle size at the right end of each branch indicates the relative number of $r p o B$ allelic types identified in a cluster. The bar indicates the length, representing 0.1 nucleotide substitutions per site. Roman numerals identify clusters and " $\mathrm{n}$ " indicates the number of isolates in a given cluster reported here (see Table 1); only selected clusters, including those identified here, are shown. For example, only 4 of the 12 Bacillus clusters previously reported are shown here. 
isolates, representing each of the 10 newly identified $r p o B$ AT (i.e., rpoB AT that had not been identified previously, as described above), and the 10 isolates for which the $r p o B$ primers (i.e., those described by Drancourt et al., 2004) did not successfully amplify the targeted $r p o B$ fragments were subsequently characterized by sequencing the $3^{\prime}$ end of the $16 \mathrm{~S}$ rRNA gene. Five and 1 of the 10 isolates representing newly identified AT were identified as Paenibacillus spp. and Bacillus spp., respectively (16S sequence data allowed genus, but not species, identification for these isolates), whereas the remaining 4 isolates were identified as Paenibacillus pumilus, Paenibacillus amylolyticus, Paenibacillus borealis, and Bacillus licheniformis (Table 1). Of the 88 isolates obtained in the study, 5 and 83 isolates represented Bacillus and Paenibacillus spp., respectively (Table 1). These Bacillus and Paenibacillus spp. isolates represented 5 and 26 rpoB AT, respectively.

All of the 10 isolates, for which the $r p o B$ primers (i.e., those described by Drancourt et al., 2004) did not successfully amplify the targeted $r p o B$ fragments, were successfully amplified by $16 \mathrm{~S}$ rDNA PCR. Six isolates shown by staining to be gram-positive rods were identified as 2 Bacillus spp. and 4 Paenibacillus spp. The remaining 4 isolates were not identified as gram-positive rods and were classified by $16 \mathrm{~S}$ rDNA sequencing as 3 Pseudomonas spp. and 1 Enterococcus sp.

\section{Raw Milk Contamination Patterns}

A total of 23 different rpoB AT were identified among the 63 isolates that were obtained from 23 heat-treated raw milk samples; raw milk samples represented 8 samples collected from tanker trucks at plant $\mathrm{C}$ and 13 samples collected from tanker trucks at plant $M$ as well as 2 samples from raw milk silos at plant M. For plant C, 12 different rpoB AT were identified among the 22 isolates subtyped (Table 2); only 2 rpoB AT were found in more than one truck load at this plant, including AT 15 (2 loads) and AT 32 (2 loads; Table 2). For plant $\mathrm{M}, 15$ different $r p o B$ AT were identified among the 35 subtyped isolates obtained from the raw milk samples collected from tank truck loads. Four rpoB AT were identified in more than one truck load, including AT 2 (3 loads), AT 15 (8 loads), AT 27 (2 loads), and AT 32 (2 loads; Table 3). Four rpoB AT were identified among the 6 isolates collected from heat-treated samples of raw milk obtained from the raw milk silos at plant M. Although one of these rpoB AT (AT 40) was isolated only from the raw milk silo samples at this plant, $3 \mathrm{AT}$ (AT 15, 21, and 27) had also been isolated from the tank truck samples at plant M (AT 15 was identified in both silos, whereas AT 21 and 27 were identified only in silos 2 and 3 , respectively).

Among the $23 \mathrm{rpoB}$ AT isolated from raw milk samples at plants C and M, 5 AT (AT 7, 15, 21, 27, and 32) were found in raw milk samples collected at both plants (Tables 2 and 3). Four of these 5 rpoB AT (AT 15, 21, 27 , and 32 ) had previously been isolated from both raw milk and pasteurized packaged products collected during the same processing run in 2 NYS fluid milk-processing plants (Huck et al., 2007), indicating survival after pasteurization for isolates with these AT.

\section{Contamination Patterns from Raw Milk to Pasteurized Packaged Products}

A total of 14 rpoB AT were identified among the 25 isolates obtained from 11 packaged product samples (representing 5 and 6 samples from plants $\mathrm{C}$ and $\mathrm{M}$, respectively). Nine and $10 \mathrm{rpoB} \mathrm{AT}$ were identified among isolates from plant $\mathrm{C}$ (10 isolates) and plant $\mathrm{M}$ (15 isolates), respectively. Five of these rpoB AT (AT $2,15,19,27$, and 35 ), representing $64 \%$ of the packaged product isolates, were identified at both plants.

At plant M, 5 rpoB AT (AT 2, 15, 21, 27, and 35) were found in both heat-treated raw milk and finished product samples. Similarly, at plant C, 3 rpoB AT (AT 15,27 , and 46) were found in both heat-treated raw milk and finished product samples. Interestingly, at plant M, isolates with AT 15 and 27 were also found in raw milk samples from tank trucks, in raw milk samples from silos, and in pasteurized packaged products, suggesting transmission of these AT from incoming tank truck raw milk loads to finished products in both plants. Allelic type 15 was also found in raw and pasteurized milk samples in plant $\mathrm{M}$ in a previous study that included 3 samplings in 3 subsequent weeks (Huck et al., 2007). Furthermore, AT 2, which was found in plant $\mathrm{M}$ only in pasteurized milk samples in each of 3 wk in a previous study (Huck et al., 2007), was found in 4 of the 6 finished product samples and 3 raw milk samples (Table 3). Importantly, all 3 of these AT (AT 2, 15, and 27) represent a specific Paenibacillus cluster (cluster XXII; Table 1). Although this cluster has not yet been classified to the species level, our data indicate that this Paenibacillus spp. is a major cause of fluid milk spoilage, particularly because cluster XXII represents $77.3 \%$ of the 88 isolates characterized here as well as $44.7 \%$ of 385 previously characterized isolates from heat-treated raw and pasteurized fluid milk samples (Huck et al., 2007).

\section{DISCUSSION}

In this study we characterized the subtype diversity of endospore-forming spoilage bacteria isolated from 
Table 2. Molecular subtypes for endospore-forming bacteria isolates obtained from raw milk tank truck loads and pasteurized packaged products at plant $\mathrm{C}^{1}$

\begin{tabular}{ll}
\hline Sample site & \multicolumn{1}{c}{$\begin{array}{c}\text { rpoB allelic types } \\
\text { (no. of isolates) }\end{array}$} \\
\hline $\begin{array}{l}\text { Heat-treated raw milk, tank trucks } \\
\text { Truck 1 }\end{array}$ \\
Truck 2 & AT32 (2) \\
Truck 3 & AT46 (3) \\
Truck 4 & AT23 (2), AT27 (1) \\
Truck 5 & AT47 (1), AT51 (2) \\
Truck 6 & AT7 (2), AT21 (1) \\
Truck 7 & AT3 (1), AT52 (1) \\
Truck 8 & AT13 (1), AT15 (2) \\
Packaged product (all in half-gallon container size) & AT15 (1), AT32 (2) \\
Skim milk in paper carton & \\
Skim milk in plastic carton & AT15 (1) \\
$2 \%$ milk in paper carton & AT46 (1), AT50 (1) \\
Homogenized milk in paper carton & AT2 (2), AT49 (1) \\
Homogenized milk in plastic carton & AT27 (1), AT35 (1), AT48 (1) \\
\hline
\end{tabular}

${ }^{1}$ All pasteurized milk samples were collected on a single production day; the 8 raw milk truck samples were collected in the 24 -h period prior to processing and thus represent the raw milk for that production day.

raw milk supplies and HTST pasteurized fluid milk products collected at 2 processing plants in NYS. Overall, our data indicate that considerable subtype diversity of endospore-forming bacteria is present in the raw and pasteurized milk supply, with members of the genus Paenibacillus appearing to be major contributors to fluid milk spoilage. Our results also highlight contributions of molecular subtyping methods for improving

Table 3. Molecular subtypes for endospore-forming bacteria isolates obtained from raw milk tank truck loads and pasteurized packaged products at plant $\mathrm{M}^{1}$

\begin{tabular}{ll}
\hline Sample site & \multicolumn{1}{c}{$\begin{array}{c}\text { rpoB allelic types } \\
\text { (no. of isolates) }\end{array}$} \\
\hline $\begin{array}{l}\text { Heat-treated raw milk, tank trucks } \\
\text { Truck 1 }\end{array}$ \\
Truck 2 & AT15 (3) \\
Truck 3 & AT15 (3) \\
Truck 4 & AT2 (1), AT15 (1), AT34 (1) \\
Truck 5 & AT15 (1), AT30 (1), AT35 (1) \\
Truck 6(a) & AT15 (1), AT32 (1) \\
Truck 6(b) & AT41 (2) \\
Truck 7(a) & AT7 (1), AT27 (2) \\
Truck 7(b) & AT1 (1), AT42 (2) \\
Truck 8 & AT15 (1) \\
Truck 9 & AT15 (2), AT31 (1) \\
Truck 10(a) ${ }^{2}$ & AT2 (1), AT15 (1), AT44 (1) \\
Truck 10(b) ${ }^{2}$ & AT2 (1), AT33 (2) \\
Heat-treated raw milk, storage silos & AT21 (1), AT27 (1), AT32 (1) \\
Silo 2 & \\
Silo 3 & AT15 (1), AT21 (1), AT40 (1) \\
Packaged product (half-gallon container size) & AT15 (1), AT27 (2) \\
Skim milk in paper carton & \\
Skim milk in plastic carton & AT2 (2) \\
2\% milk in paper carton & AT15 (1), AT39 (1), AT45 (1) \\
Homogenized milk in paper carton & AT15 (1), AT19 (1), AT38 (1) \\
Homogenized milk in plastic carton & AT2 (1), AT27 (1), AT35 (1) \\
Homogenized milk in paper carton ${ }^{3}$ & AT2 (1), AT21 (1), AT36 (1) \\
\hline 1 AT1) & AT2 (1)
\end{tabular}

${ }^{1}$ All pasteurized milk samples were collected on a single production day; the 13 raw milk truck samples and 2 raw milk silo samples were collected in the 48-h period prior to processing and thus represent the raw milk for that production day.

${ }^{2}$ Tank truck contributed more than one truck load on this particular processing day (letters signify different load in the same truck).

${ }^{3}$ Quart container size. 
our understanding of the ecology and transmission of endospore-forming spoilage organisms in dairy and food processing systems.

\section{rpoB Sequencing Allows for Rapid and Economical Characterization and Subtyping of Endospore- Forming Dairy Spoilage Organisms}

Application of molecular subtyping methods, including PFGE, ribotyping, and other banding pattern-based methods, has been critical for gaining a better understanding of the transmission of foodborne pathogens and for reducing transmission of these pathogens (Swaminathan et al., 2001). Some endospore-forming food spoilage microorganisms have been characterized by banding pattern-based subtyping methods (Schraft et al., 1996; Svensson et al., 1999), but these subtyping methods have been applied less frequently to the exploration of spoilage microorganism transmission, at least partly because of the cost of many modern molecular subtyping methods (Olive and Bean, 1999). Recent advances in the development of DNA sequencing-based subtyping methods, including the development of an $r p o B$ sequencing-based subtyping method for Bacillus and Paenibacillus spp., now offer improved opportunities to probe the transmission and ecology of these organisms with an economical subtyping method. In addition, the development and availability of an $r p o B$ sequence database that includes a diverse collection of $>500$ Bacillus and Paenibacillus spp. isolates (this study; Durak et al., 2006; Huck et al., 2007) comprising $>110$ rpoB AT that have also been characterized by $16 \mathrm{~S}$ rDNA sequencing allows for characterization of many Bacillus and Paenibacillus isolates to the genus and species level. Even if species-level identification is not possible, which is currently typical for many Paenibacillus isolates, $r p o B$ sequence data still allow for identification of distinct Paenibacillus clusters, which are likely to represent different species. Furthermore, these sequencing-based subtyping strategies allow simple Web-based data curation as well as reliable and robust comparison of subtype data generated by different research groups (Aanensen and Spratt, 2005).

\section{Paenibacillus spp. Are Major Contributors to Fluid Milk Spoilage}

Overall, our data indicate that a considerable subtype diversity of endospore-forming bacteria, particularly those representing the genera Bacillus and Paenibacillus, are present in raw and processed milk. In conjunction with previous studies (Huck et al., 2007), our data specifically indicate that a large proportion of endospore-forming bacteria isolated from raw and pasteur- ized fluid milk represent Paenibacillus spp. In particular, most of the Paenibacillus isolates from milk characterized here and previously (Huck et al., 2007) represent a specific Paenibacillus subgroup (cluster XXII). Bacillus spp., as well as Paenibacillus spp., are known for their ability to form heat-resistant endospores that can survive heat-treatment processing conditions (Collins, 1981; Huck et al., 2007). Although a number of studies have identified Bacillus spp. in milk from the farm (Crielly et al., 1994; Sutherland and Murdoch, 1994; Lukasova et al., 2001) and the processing plant, including in processing plant raw milk supplies (Lin et al., 1998; Huck et al., 2007) and in pasteurized packaged products (Griffiths and Phillips, 1990; Lin et al., 1998; Douglas et al., 2000; Fromm and Boor, 2004; Durak et al., 2006; Huck et al., 2007), Paenibacillus has only recently been identified as an important contributor to fluid milk spoilage that can be found in both raw and pasteurized fluid milk (Huck et al., 2007). The present study provides direct subtype-based evidence that Paenibacillus spp. present in raw milk (particularly those representing cluster XXII) can be transmitted to finished pasteurized products. Similar to Bacillus spp., Paenibacillus spp. that are able to grow under refrigeration temperatures (typically $<6^{\circ} \mathrm{C}$ ) are of particular concern as spoilage microorganisms in fluid milk products. Bacterial growth patterns in the heat-treated raw milk samples reported here and previously (Huck et al., 2007) indicate that Paenibacillus spp. can grow in milk stored at $6^{\circ} \mathrm{C}$. This growth behavior is consistent with reports that a number of Bacillus spp., including B. cereus (Dufrenne et al., 1995; te Giffel et al., 1995), Bacillus weihenstephanensis (Pacova et al., 2003), and Bacillus circulans (Shehata and Collins, 1971), as well as Paenibacillus spp. (Huck et al., 2007) are psychrotolerant.

The data reported here indicate that Paenibacillus and Bacillus spp. are commonly present in the raw milk entering processing plants. These microorganisms may contaminate raw milk at various points during production (e.g., milking, raw milk storage and handling on the farm) as well as possibly during loading of tank trucks and transport. Specifically, aerobic spore-formers of the genus Bacillus are ubiquitous and have been isolated from dairy farm environments, including silage (te Giffel et al., 2002), pasture (Slaghuis et al., 1997), soil (Christiansson et al., 1999), and fecal material (Labots et al., 1965). Environmental contamination of udders (Lukasova et al., 2001) and milking equipment (McKinnon and Pettipher, 1983) may lead to the presence of Bacillus spp., including B. licheniformis and B. cereus, in bulk tanks on dairy farms (Griffiths and Phillips, 1990; Crielly et al., 1994). In addition, a previous study by our group (Huck et al., 2007) has found 
preliminary evidence for the persistence of selected Paenibacillus and Bacillus subtypes in processing plants. Thus, contamination of fluid milk with endospore-forming spoilage microorganisms may also occur at the processing plant, either pre- or postpasteurization.

\section{CONCLUSIONS}

As the dairy industry progresses toward extending the shelf life of conventionally pasteurized HTST fluid milk products, the presence of endospore-forming bacteria capable of surviving pasteurization and growing at refrigeration temperatures is a specific biological hurdle limiting the extension of shelf life past $14 \mathrm{~d}$ (Fromm and Boor, 2004; Durak et al., 2006; Huck et al., 2007). Our data clearly show that endospore-forming bacteria, particularly Paenibacillus spp., are present in raw milk tank truck loads entering the processing plant. Known for their ability to form heat-resistant spores, these endospore-forming bacteria can survive commercial HTST pasteurization and grow under refrigeration temperatures, ultimately spoiling processed products. Molecular subtyping methods provide the reproducibility and sensitive discrimination needed to identify and track psychrotolerant endospore-forming bacteria through dairy production and processing systems. Ultimately, further extension of the shelf life of fluid milk products will require elimination, or at least improved control, of endospore-forming psychrotolerant spoilage organisms. Because our data suggest raw milk as one likely source of spoilage bacteria, control of these organisms represents a considerable challenge that will likely require a comprehensive farm-to-table approach, similar to the framework proposed for control of many foodborne pathogens.

\section{ACKNOWLEDGMENTS}

This project was supported by the New York State Milk Promotion Advisory Board through the New York State Department of Agriculture and Markets and New York State dairy farmers committed to production of high-quality dairy products. The authors thank the management and employees of the 2 dairy plants involved in the study, as well as Renato Orsi for assistance with the phylogenetic analyses, Martin Wiedmann for helpful conversations and critical review of the manuscript, and staff members of the Cornell University Milk Quality Improvement Program for technical support.

\section{REFERENCES}

Aanensen, D. M., and B. G. Spratt. 2005. The multilocus sequence typing network: mlst.net. Nucleic Acids Res. 33:W728-W733.

Aires-de-Sousa, M., K. Boye, H. de Lencastre, A. Deplano, M. C. Enright, J. Etienne, A. Friedrich, D. Harmsen, A. Holmes, X.
W. Huijsdens, A. M. Kearns, A. Mellmann, H. Meugnier, J. K. Rasheed, E. Spalburg, B. Strommenger, M. J. Struelens, F. C. Tenover, J. Thomas, U. Vogel, H. Westh, J. Xu, and W. Witte. 2006. High interlaboratory reproducibility of DNA sequencebased typing of bacteria in a multicenter study. J. Clin. Microbiol. 44:619-621.

Ash, C., A. E. Farrow, S. Wallbanks, and M. D. Collins. 1991. Phylogenetic heterogeneity of the genus Bacillus revealed by comparative analysis of small-subunit-ribosomal RNA sequences. Lett. Appl. Microbiol. 13:202-206.

Ash, C., F. G. Priest, and M. D. Collins. 1993. Molecular identification of rRNA group 3 bacilli (Ash, Farrow, Wallbanks and Collins) using a PCR probe test. Proposal for the creation of a new genus Paenibacillus. Antonie Van Leeuwenhoek 64:253-260.

Christiansson, A., J. Bertilsson, and B. Svensson. 1999. Bacillus cereus spores in raw milk: Factors affecting the contamination of milk during the grazing period. J. Dairy Sci. 82:305-314.

Claus, D., and D. Fritze. 1989. Taxonomy of Bacillus. Pages 5-26 in Biotechnology Handbooks. Vol. 2, Bacillus. C. R. Harwood, ed. Plenum Press, New York, NY.

Collins, E. B. 1981. Heat resistant psychrotrophic organisms. J. Dairy Sci. 64:157-160.

Crielly, E. M., N. A. Logan, and A. Anderton. 1994. Studies on the Bacillus flora of milk and milk products. J. Appl. Bacteriol. 77:256-263.

Douglas, S. A., M. J. Gray, A. D. Crandall, and K. J. Boor. 2000. Characterization of chocolate milk spoilage patterns. J. Food Prot. 63:516-521.

Drancourt, M., V. Roux, P. E. Fournier, and D. Raoult. 2004. rpoB gene sequence-based identification of aerobic Gram positive cocci of the genera Strepococcus, Enterococcus, Gemella, Abiotrophia and Granulicatella. J. Clin. Microbiol. 42:497-504.

Dufrenne, J., M. Bijwaard, M. te Giffel, R. Beumer, and S. Notermans. 1995. Characteristics of some psychrotrophic Bacillus cereus isolates. Int. J. Food Microbiol. 27:175-183.

Durak, M. Z., H. I. Fromm, J. R. Huck, R. N. Zadoks, and K. J. Boor. 2006. Development of molecular typing methods for Bacillus spp. and Paenibacillus spp. isolated from fluid milk products. J. Food Sci. 71:50-56.

Eiroa, M. N., V. C. Junqueira, and F. L. Schmidt. 1999. Alicyclobacillus in orange juice: Occurrence and heat resistance of spores. J. Food Prot. 62:883-886.

Frank, J. F., and A. E. Yousef. 2004. Tests for groups of microorganisms. Pages 227-248 in Standard Methods for the Examination of Dairy Products. 17th ed. M. Wehr, ed. Am. Public Health Assoc., Washington, DC.

Fromm, H. I., and K. J. Boor. 2004. Characterization of pasteurized fluid milk shelf-life attributes. J. Food Sci. 69:207-214.

Fugett, E. B. 2006. Development of molecular subtyping databases to improve control of Listeria monocytogenes. MS Thesis. Cornell University, Ithaca, NY.

Griesen, K., M. Loeffelholz, A. Purohit, and D. Leong. 1994. PCR primers and probes for the 16S rRNA gene of most species of pathogenic bacteria, including bacteria found in the cerebrospinal fluid. J. Clin. Microbiol. 32:335-351.

Griffiths, M. W., and J. D. Phillips. 1990. Incidence, source and some properties of psychrotrophic Bacillus spp. found in raw and pasteurized milk. J. Soc. Dairy Technol. 43:62-66.

Guinebretiere, M. H., O. Berge, P. Normand, C. Morris, F. Carlin, and C. Nguyen. 2001. Identification of bacteria in pasteurized zucchini purees stored at different temperatures and comparison with those found in other pasteurized vegetable purees. Appl. Environ. Microbiol. 67:4520-4530.

Huck, J. R., N. H. Woodcock, R. D. Ralyea, and K. J. Boor. 2007. Molecular subtyping and characterization of psychrotolerant endospore-forming bacteria in two New York State fluid milk processing systems. J. Food Prot. 70: (in press)

Kabuki, D. Y., A. Y. Kuaye, M. Wiedmann, and K. J. Boor. 2004. Molecular subtyping and tracking of Listeria monocytogenes in Latin-style fresh-cheese processing plants. J. Dairy Sci. 87:2803-2812. 
Klappenbach, J. A., P. R. Saxman, J. R. Cole, and T. M. Schmidt. 2001. rrndb: The Ribosomal RNA Operon Copy Number Database. Nucleic Acids Res. 29:181-184.

Labots, H., G. Hup, and T. E. Galesfoot. 1965. Bacillus cereus in raw and pasteurized milk. III. The contamination of raw milk with Bacillus cereus spores during its production. Neth. Milk Dairy J. 19:191-221.

Lin, S., H. Schraft, J. A. Odumeru, and M. W. Griffiths. 1998. Identification of contamination sources of Bacillus cereus in pasteurized milk. Int. J. Food Microbiol. 43:159-171.

Logan, N. A., and R. C. Berkeley. 1984. Identification of Bacillus strains using the API system. J. Gen. Microbiol. 130:1871-1882.

Lukasova, J., J. Vyhnalkova, and Z. Pacova. 2001. Bacillus species in raw milk and in the farm environment. Milchwissenschaft 56:609-611.

McGinnis, S., and T. L. Madden. 2004. BLAST: At the core of a powerful and diverse set of sequence analysis tools. Nucleic Acids Res. 32:W20-W25.

McKinnon, C. H., and G. L. Pettipher. 1983. A survey of sources of heat-resistance bacteria in milk with particular reference to psychrotrophic spore-forming bacteria during transport, storage and processing. J. Dairy Res. 50:163-170.

Meer, R. R., J. Baker, F. W. Bodyfelt, and M. W. Griffiths. 1991. Psychrotrophic Bacillus spp. in fluid milk products: A review. J. Food Prot. 54:969-979.

Odumeru, J. A., M. Steele, L. Fruhner, C. Larkin, J. Jiang, E. Mann, and W. B. McNab. 1999. Evaluation of accuracy and repeatability of identification of food-borne pathogens by automated bacterial identification systems. J. Clin. Microbiol. 37:944-949.

Olive, D. M., and P. Bean. 1999. Principles and applications of methods for DNA-based typing of microbial organisms. J. Clin. Microbiol. 37:1661-1669.

Pacova, Z., P. Svec, L. P. Stenfors, M. Vyletelova, and I. Sedlacek. 2003. Isolation of psychrotolerant species Bacillus cereus from raw cow's milk. Czech J. Anim. Sci. 48:93-96.

Pettipher, G. L., M. E. Osmundson, and J. M. Murphy. 1997. Methods for the detection and enumeration of Alicyclobacillus acidoterrestris and investigation of growth and production of taint in fruit juice and fruit juice-containing drinks. Lett. Appl. Microbiol. 24:185-189.

Pires, M. N., and L. Seldin. 1997. Evaluation of Biolog system for identification of strains of Paenibacillus azotofixans. Antonie Van Leeuwenhoek 71:195-200.

Ralyea, R. D., M. Wiedmann, and K. J. Boor. 1998. Bacterial tracking in a dairy production system using phenotypic and ribotyping methods. J. Food Prot. 61:1336-1340.

Rothman, R. E., M. D. Majmudar, G. D. Kelen, G. Madico, C. A. Gaydos, T. Walker, and T. C. Quinn. 2002. Detection of bacteremia in emergency department patients at risk for infective endocarditis using universal 16S rRNA primers in a decontaminated polymerase chain reaction assay. J. Infect. Dis. 186:1677-1681.
Rozas, J., and R. Rozas. 1999. DnaSP version 3: An integrated program for molecular population genetics and molecular evolution analysis. Bioinformatics 15:174-175.

Schraft, H., M. Steele, B. McNab, J. Odumeru, and M. W. Griffiths. 1996. Epidemiological typing of Bacillus spp. isolated from food. Appl. Environ. Microbiol. 62:4229-4232.

Shehata, T. E., and E. B. Collins. 1971. Isolation and identification of psychrotrophic strains of Bacillus from milk. Appl. Environ. Microbiol. 21:466-473.

Slaghuis, B. A., M. C. T. Giffel, R. R. Beumer, and G. Andre. 1997. Effect of pasturing on the incidence of Bacillus cereus spores in raw milk. Int. Dairy J. 7:201-205.

Sneath, P. H. A. 1986. Endospore-forming Gram-positive rods and cocci. Pages 1104-1207 in Bergey's Manual of Systematic Bacteriology. Vol. 2. The Williams and Wilkins Co., Baltimore, MD.

Sutherland, A. D., and R. Murdoch. 1994. Seasonal occurrence of psychrotrophic Bacillus species in raw milk, and studies on the interactions with mesophilic Bacillus spp. Int. J. Food Microbiol. 21:279-292.

Svensson, B., A. Eneroth, J. Brendehaug, and A. Christiansson. 1999 Investigation of Bacillus cereus contamination sites in a dairy plant with RAPD-PCR. Int. Dairy J. 9:903-912.

Swaminathan, B., T. J. Barrett, S. B. Hunter, and R. V. Tauxe. 2001. PulseNet: The molecular subtyping network for foodborne bacterial disease surveillance, United States. Emerg. Infect. Dis. 7:382-389.

te Giffel, M. C., R. R. Beumer, M. H. Bonestroo, and F. M. Rombouts. 1996. Incidence and characterization of Bacillus cereus in two dairy processing plants. Neth. Milk Dairy J. 50:479-492.

te Giffel, M. C., R. R. Beumer, B. A. Slaghuis, and F. M. Rombouts. 1995. Occurrence and characterization of (psychrotrophic) Bacillus cereus on farms in the Netherlands. Neth. Milk Dairy J. 49:125-128.

te Giffel, M. C., A. Wagendorp, A. Herrewegh, and F. Driehuis. 2002. Bacterial spores in silage and raw milk. Antonie Van Leeuwenhoek 81:625-630.

Teng, J. L., P. C. Woo, K. W. Leung, S. K. Lau, M. K. Wong, and K. Y. Yuen. 2003. Pseudobacteraemia in a patient with neutropenic fever caused by a novel Paenibacillus species: Paenibacillus hongkongensis sp. nov. Mol. Pathol. 56:29-35.

van Netten, P., and J. M. Kramer. 1992. Media for the detection and enumeration of Bacillus cereus in foods: A review. Int. J. Food Microbiol. 17:85-99.

Wiedmann, M. 2002. Subtyping of bacterial foodborne pathogens. Nutr. Rev. 60:201-208.

Wisotzkey, J. D., P. Jurtshuk Jr., G. E. Fox, G. Deinhard, and K. Poralla. 1992. Comparative sequence analyses on the 16S rRNA (rDNA) of Bacillus acidocaldarius, Bacillus acidoterrestris, and Bacillus cycloheptanicus and proposal for creation of a new genus, Alicyclobacillus gen. nov. Int. J. Syst. Bacteriol. 42:263-269. 